\title{
From effective accounting and reporting to efficient outsourcing
}

\author{
Daria MEYR ${ }^{1}$ \\ ${ }^{1}$ Technische Universität Dresden, Chair of Environmental Management and Accounting, Dresden \\ Germany
}

\begin{abstract}
This study aims to identify an effective management accounting and reporting concept for efficient outsourcing performance in sustainable organizations. Existing reporting norms of the "Systemanalyse und Programmentwicklung (SAP)" platform, used in JSC "Russian Railways" (further Russian Railways) were analysed. Thereby, in the paper a method of the formation of internal management accounting and reporting on the costs of outsourcing were developed. Currently, the analysis of the reports and effectiveness of outsourcing is based on the technique comparison "costs on outsourcing should be less than the cost of own units". Effective analysis should include not one, but several factors and be based on multi-criteria approach. The main influence on the variation of such determinants as cost, productivity and staff members outsourcing has when the volume of production and prices are constant. According to the features of railway transport enterprises, existing method has been completed with statistical. It shows how outsourcing changed the performance of the company and by what factors - the average cost, or productivity, or staffing or due to variations of all three factors simultaneously. Further, the results of quantitative data analysis will be used to identify an effective management accounting in sustainable organizations while supporting the development of outsourcing.
\end{abstract}

Key words—outsourcing, cost accounting, managerial reporting, railway transport

\section{INTRODUCTION}

Since 2008, the impacts of the financial crisis had a great influence on the global economy. Along with a variety of challenges, e.g. availability and prices of resources, technological change and strong globalisation of the market, the pressure on the financial structures increased for organizations and companies. Therefore, it is crucial for them to use modern management instruments and methods to reduce costs, optimize financial and corporate structures and increase the efficiency.

According to the law of the firm, developed by Coase [2], an organization or company is efficient, when the costs of their business transactions are less than the costs of similar operations carried out by the market. Thereby, a limit is reached, when the costs of non-core business processes are higher than on the market.

One of the instruments that are appropriate to overcome this limitation is "outsourcing". By outsourcing companies can reduce their costs and at the same time simplify their corporate structure. Furthermore, the creation of innovations and the development of new technologies are supported [1].

However, still in some major industry countries guidelines that regulate, control and increase the efficiency of outsourcing do not exist. For example, there is even no definition of "outsourcing" in Russian legislation.

Railway transport is one of the most important components of the Russian's economy. This is one of the key strategic state mechanism that supports the performance of all industries. Railways have not only transport and communication function, but are "donors" of some Russian regions. Therefore the role of the railway transport in Russia is very significant, as it is a great component of railway logistic in the prices on products, works, services. Outsourcing was intended to reduce the costs of non-core business processes and to focus on the core business - transportation processes. Nevertheless, more than ten years practice showed, that to improve the application of outsourcing on Russian railways it is crucial to develop of methods of accounting and controlling of costs. The lack of managerial control and accounting system for the calculation of the costs on outsourcing, including all transaction costs leads to inefficient projects.

As a best practice example, a group of experts in cooperation with leading organizations (e.g. IBM Deutschland Business Services GmbH; Cognizant Technology Solutions GmbH; 
PricewaterhouseCoopers AG WPG; ect.) developed a norm for "outsourcing of technology driven knowledge-intensive business services" in Germany in 2010 (DIN SPEC 1041 of the Deutsches Intitut für Normung e. V.). The included guidelines for outsourcing processes mainly focus to assist small and medium sized enterprises. Major issues are the auditing and (cost-) controlling of the outsourcing processes.

Furthermore, Lamminmaki [12] notes that the main principle of the development of outsourcing has to be a centralized control of service providers and accounting of the costs. Modern accounting and controlling systems are one of the most important functions of management and an important source of information for management decision making. An absence of cost controlling and accounting would guarantee the failure of any outsourcing project.

\section{METHOD}

The concept of outsourcing was formulated in the studies of Anglo-American literature. One of the most common definitions of outsourcing and its main principles was developed by Heywood in 2001 [10]. According to him, outsourcing is a way of corporate business optimization by the concentration of resources on the main performance and transferring non-core functions (business processes). He defined that the main principle of outsourcing is a long-term contract with external specialized organizations, who own the relevant know-how, experience and technical equipment.

The theoretical background of outsourcing can be explained in terms of the classical theory of microeconomics. The division of labor is an important principle of an effectively organized economic system [17]. In 1867, Marx scientifically substantiated the historical inevitability and progressive division of labor, determining its value for each economic system.

An overview of this research area showed that outsourcing is mostly considered from the view of transaction cost theory (TCE) $[2,23]$ and resource-based view (RBV) [1].

According to the TCE paradigm, the correlation of the costs of implementing transactions through the market and within the firm is determined a choice of "make or buy" [23].

The RBV approach became a new standard in the development of competitive analysis. One of the strengths of the RBV is that it explains in an understandable way why companies are successful as well as an application of a competence-based approach to practice and development of competitive strategies of the organization.

According to international studies $[9,10,14]$ outsourcing is one of the priority tools for improving corporate efficiency. Thereby, outsourcing significantly improves the business performance and optimizes corporate business processes.

A variety of international researchers, e.g. Dabhilkar and Bengtsson (2008), Dankbaar (2007), Jiang et al. (2007), Power et al. (2006), Larson and Kulchitsky (1999), Gilley and Rasheed (2000), Jiang et al.(2006) and Salimath et al.(2008) $[3,4,7,11,12,16,19]$ analysed the positive effects of outsourcing on the elasticity of production and the market value of sales as well as the negative impact on innovation capacity, quality and the speed of performance.

In the paper of Lamminmaki [14] interview and survey data have been collected to research the nature and antecedents of accounting systems involved in outsourcing decision-making and control in the hotel industry. It has been found that there is "considerable cross-hotel variation in the degree of accounting system involvement in outsourcing management" [14].

In spite of the fact that there are a lot of studies for outsourcing, within the analysis, a critical need in centralizing the outsourcing processes, accounting and reporting methods of costs on Russian Railways was identified.

The history of outsourcing on railway transport in Russia is older than ten years and the list of professions, jobs and services for outsourcing counts eighty positions [20]. Outsourcing is an effective tool for optimizing operational and financial structure of the business entity actively used in railway transport. The use of outsourcing allows the company to concentrate on the main business - transportation processes, to raise its efficiency, increase the quality of production and services by rendering tasks or business processes [16].

Outsourcing is applied on the majority of railway branches, but not everywhere it is possible to consider its application optimum as it increases the costs and impairs the quality of works and services of Russian Railways. An integral part of any economic process is an effective use of financial resources. Nevertheless, in practice, Russian Railways mainly determined and accounted for the context of managerial accounting only "visible" costs on outsourcing. 
Formation, development and organization of managerial accounting was researched by a lot of international authors. Drury [5] describes managerial accounting as identification, measurement, data collection, analysis, interpretation and communication of required information to manage business processes. The main purpose of cost accounting is the costing of production and services. Cost accounting is a managerial accounting in combination with financial reports.

According to the approach of Russian researcher Sheremet [20], managerial accounting is a subsystem of accounting that within one organization provides its administrative staff information, used for planning, management and control of organization. Management accounting covers all the accounting information necessary for management within the organization.

The analysis of different approaches to the definitions of managerial accounting in this paper ascertained a conclusion that it is a system, primarily aimed to obtain managers accurate information to increase the quality of their economic and financial decisions.

Numerous publications of researchers had a different range of opinions, nevertheless accounting and analytical support of outsourcing processes on Russian Railways has not yet been sufficiently developed.

The efficiency of the outsourcing transaction on Russian Railways is determined as the difference between the results of outsourcing (organization provided outsourcing services) and incurred costs of Russian Railways. The method of calculation was developed by Railways Institute in 2006. It described in details the regulations on the use of outsourcing in different branches. Furthermore, it also describes the preparation of the decision on the use of outsourcing and performance monitoring of outsourced works, services.

In this study, the methods of expert judgments and comparative analysis showed that in the company there is no detailed account of the costs for establishing the necessary legal framework for the implementation outsourcing cooperation.

While the analysis of expert judgments identified that for outsourcing on all phases of the life cycle of the outsourcing contract it is necessary to consider all incurred costs, which are determined by the structure formation of the outsourcing agreement (Fig. 1).

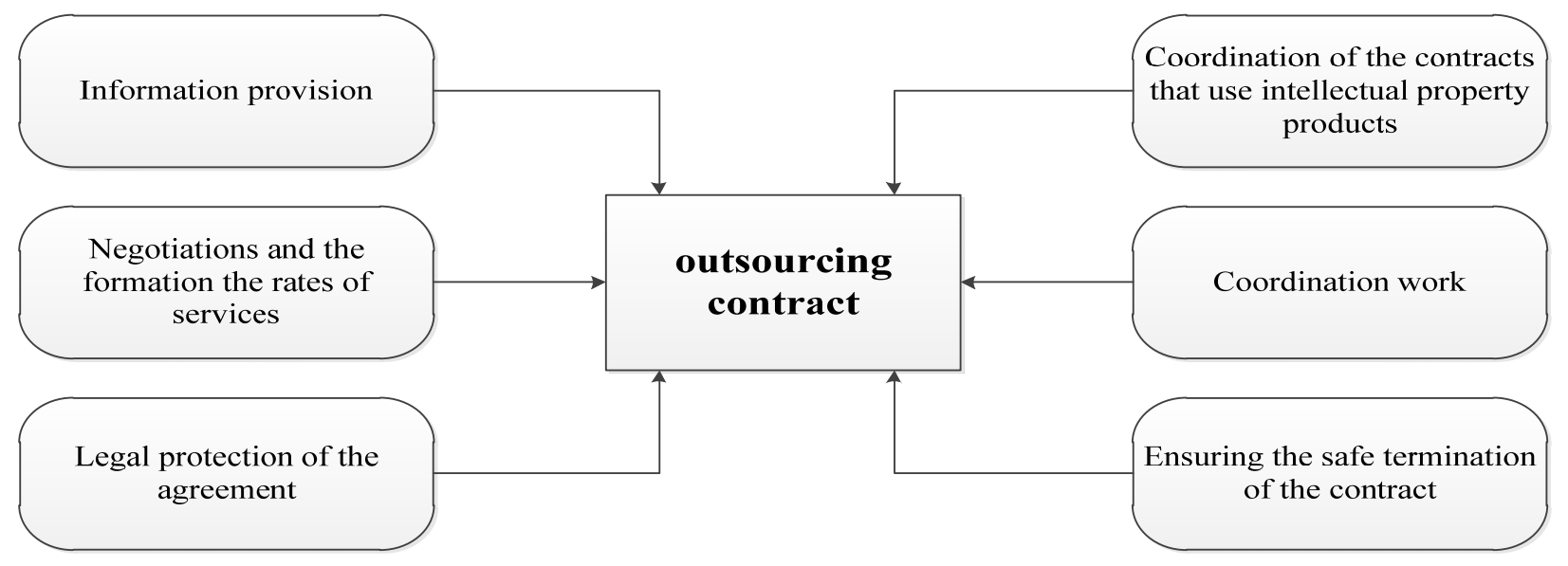

Figure 1: Structure of the lifecycle of outsourcing contract [6]

The conclusion of agreements involves risks, which must be analyzed, identified and as far as possible minimized in the process of outsourcing contractual relations.

The results of the analysis showed, that the management of Russian Railways does not consider a significant amount of labor costs that were included on the proposed lifecycle of outsourcing contract (Fig. 1). To ensure the legal protection of the outsourced contract lawyer staff involved for the examination of the contract, monitoring the terms and conditions etc. are crucial. Ensuring the information security provided by lawyer and information departments is necessary too. By solving the problems of intellectual property not only members of the lawyer departments, but also employees of departments of intellectual property are involved. That, undoubtedly, leads to the diversion of labor resources and increases additional costs. 
Formation rates of services requires a significant diversion of resources, as this procedure involves high time costs. An important role play highly qualified economists, as well as mid-level managers. However, that increases the costs of the formation of the contract with outsourcers.

Furthermore, in this sector of responsibility are tenders, competitions and market analysis, which also effect the labor costs of employees involved in outsourcing contracts on Russian Railways.

A very significant part takes the coordination work, involving not only the implementation of an effective monitoring of activities in cooperation between Russian Railways and service providers. Moreover, it is the implementation of control measures for the main indicators of their work. In this regard, the derivation of labor going, e.g., the work that has to be paid.

We have to assume that not all the contracts are fully implemented. Usually the reason is insufficient quality of works and services. Further reasons might be changes of the economic situation in the country. Therefore, an agreement should provide feasibility of anticipatorily termination of the outsourcing contract. This will minimize the risks arising from the termination of the transaction.

Within the analysis, a critical need in centralizing the outsourcing processes on Russian Railways was identified.

Thus, at present, all the labor costs of employees involved in the preparation and maintenance of the outsourcing contract, in managerial accounting are not directly related to the formation of the outsourcing relationship and lost in the total fixed or operating costs. In such system, it is impossible to conduct additional analysis.

In this regard, in this paper it is proposed managerial accounting to allocate the staff costs of involved employees directly to the exact outsourcing contract. This will allow to conduct a detailed analysis of the effectiveness of labor. This, in turn, has a positive effect on the optimization of structural work of the departments.

The volume of labor costs to outsourcing processes is proposed to calculate with a developed formula (1):

$$
L C_{\text {out }}=\frac{\bar{s}}{t} \times t_{\text {out }}
$$

LCout - labor costs for the employees supported outsourcing processes(thousand rubles);

$\bar{S}$-average monthly salary of involved employes (thousand rubles);

$t$ - monthly spent time (hour);

tout - time spent directly to support outsourcing processes (hour).

In the initial phase of the contractual process, it is recommended to create a method of regulated norms of time spent on supporting outsourcing contracts. On the base of such norms there has to be the card of time costs (photo of the work day) and the average norms for the relevant period of time have to be set.

In the future, the time spent to support the outsourcing agreement is proposed to regulate the relevant technical requirements and prescribe norms for time-consuming of the employer for each type of outsourcing contract.

Then, the total costs will be determined as the sum of multiplication of labor costs (on support outsourced processes) on the number of involved employees.

Thereby, these costs can be analysed in various ways, including in the way of "price" of legal and controlling supporting outsourcing contracts for Russian Railways. Moreover, the specification of costs on outsourcing will increase the efficiency of decision-making. Furthermore, it will provide access to information, which allows to increase quality, reduce price, labor costs and increase the transparency of the industry.

\section{RESULTS AND DISCUSSION}

In this study the report forms of managerial accounting, reflecting the costs of Russian Railways were analysed. The analysis showed the absence of the information for financial analysis and decision-making. All the costs on outsourcing are calculated in the category "other costs". Since the financial analysis is an integral part of an effective mechanism for outsourcing in this paper proposes a consolidation of the costs categories on outsourcing for the creation of the managerial reporting form (table 1). The proposed data will contribute to the efficiency analysis of financial results and support decision-making processes. 
Nowadays there are two main approaches to measurement and assessment the efficiency of outsourcing: single-criteria and multiple-criteria analysises. Within the single-criteria approach the influence of outsourcing only on one indicator of the enterprise is estimated: economy or additional income. While multiple-criteria approach the influence of outsourcing on different characteristics of production and economic activity of the enterprise is estimated.

Single-criteria approach were developed first. Therefore, it is important to note that, although the term "outsourcing" has appeared in the common research and practical language relatively recently, substantially similar phenomenon existed in the economy of Russia from the period of planned economy. This phenomenon called "the change of specialization of production". To assess 


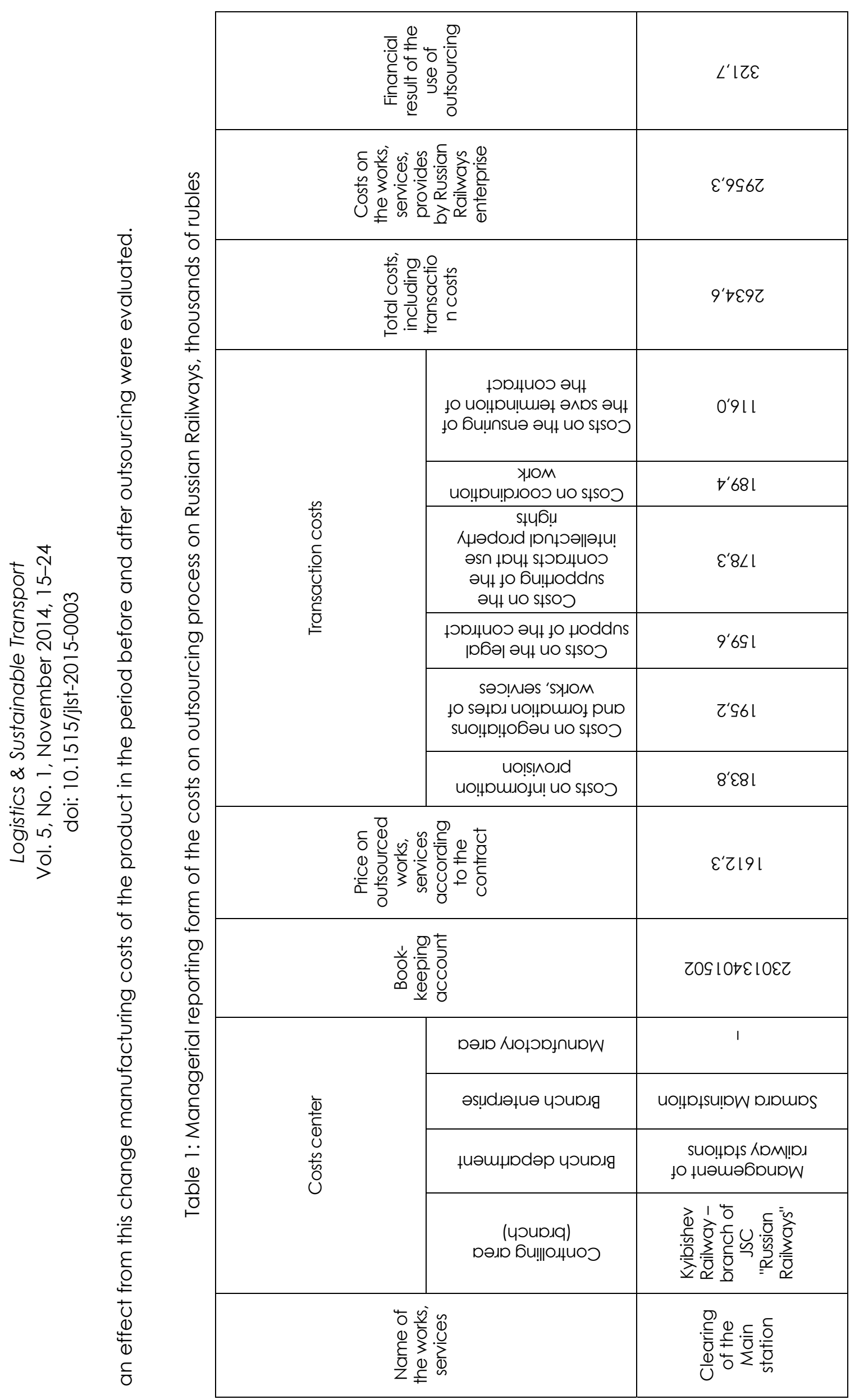


In particular, this formula do not take into account such important disadvantages of outsourcing as: dependency from outsourcer, loss of competencies, the impossibility of complete control over the quality of process, etc. Understanding of the weaknesses of single-criterion approach led to the appearance of multi-criteria methods. Structurally, they all have the form of assessment criteria.

Kotliarov (2010) [13] notes the weaknesses of multi-criteria approach. According to him "... it is existing the problem of "compensation", as in every additive technique. The deterioration of the value of one or more criteria can be compensated by an increase of the value of other criteria, and as a result the cumulative effect of outsourcing can be positive ...".

Base on the research we propose an alternative approach to the analysis of outsourcing which would eliminate the shortcomings inherent in the approaches, used today, i.e. would consider not one, but several factors (unlike single-criteria approach), and excluding compensation of the factors (unlike multi-criteria) (equations 2, 3, 4 and 5).

As it was said above, the new approach will take into account not one, but several factors and was developed on the basis of multi-criteria approach, thus exclude the possibility of compensation of factors.

Outsourcing has the main influence on the variation of such determinants as cost, productivity and staff members when the volume of production and prices are constant. According to the features of railway transport enterprises, the existing method has been completed with statistical approach. An effect of outsourcing can be estimated by the influence of the value change of different factors.

$$
E=\Delta(S \times W \times N)
$$

where:

E - effect (losses) (thousand rubles);

$\Delta$ - value change of the indicators

$S$ - average primary cost (thousand rubles);

$\mathrm{W}$ - labor productivity (goods/hoursxemployees);

$\mathrm{N}$ - number of staff members (employees).

$$
E=(S+\Delta S) \times\left(W^{2}+\Delta W^{2}\right) \times\left(N+\Delta W^{2}\right)-S^{-} \times W^{-} \times N^{-}
$$

or

$$
E=S^{-} \times V^{+} \times N^{+}-S^{-} \times H^{-} \times N^{-}
$$

where:

upper value $«+»)$ - a posteriori;

$《(-)$ - a priori.

$$
E= \pm W^{+} \times W^{+} \times \Delta S \pm S^{-} \times W^{+} \times \Delta W \pm S^{-} \times W^{-} \times \Delta R^{2}=E_{1} \pm E_{2} \pm E_{\mathbb{Q}}
$$

where:

upper value «+» - a posteriori;

«- - - a priori.

Where:

$\mathrm{E}_{1}$ - effect (losses) from the variation of average prime cost (thousand rubles);

$\mathrm{E}_{2}$ - effect (losses) from the variation of labor productivity (thousand rubles);

$\mathrm{E}_{3}$ - effect (losses) from the variation of staff members (thousand rubles);

$\mathrm{E}$ - total effect (losses) from the variation of all three factors (thousand rubles). 
Proposed approach shows how positive, or negative outsourcing changed the performance of the company and by which factors - the average primary cost, or productivity, or staffing or due to variations of all three factors simultaneously.

The organization of outsourcing in Russian Railway should represent a flexible element of an economic mechanism which is constantly analysed and changed so as to find the best variant, providing decrease in operational costs of the organization.

In our research we found out, that to achieve advantages and to meet the requirements of outsourcing applications, it is necessary to concentrate on the following directions of its development:

- transition from outsourcing of separate technological operations to outsourcing of production cycles connected with rendering of finished kinds of works and services;

- increase in geographical scales of outsourcing application.

Thereby, the forms of outsourcing can be very versatile.

Thus, the potential of the outsourcing mechanism in Russian Railways is great. If managers of the company follow the above described recommendations, it will allow obtaining statistical data about all the costs of the company and will lead to making justified management decisions in the field of outsourcing.

The proposed approaches for improving the organisational and methodological aspects of accounting and analysing of the costs will provide information to stakeholders at different levels and improve the efficiency of financial and economic activities.

The use of described classification of transaction costs will lead to an adjustment of the costs of railway companies on outsourcing and increase its profitability. Thereby, these costs can be analyzed in various ways, including in the way of "price" of legal and controlling supporting outsourcing contracts for Russian Railways. Moreover, the specification of costs on outsourcing will do decision-making more efficient. Furthermore, provide access to information, which allows increase quality, reduce price, labor costs and increase the transparency of the industry.

\section{REFERENCES}

1. Barney, J., (1991). Firm resources and sustained competitive advantage. Journal of Management. 17 (1), 99-121.

2. Coase, R., (1937). The nature of the firm. Economics. 4, 386-405.

3. Dabhilkar, M., Bengtsson, L., (2008). Invest or divest? On the relative improvement potential in outsourcing manufacturing. Production Planning \& Control. 19 (3), 212-228.

4. Dankbaar, B., (2007). Global sourcing and innovation: the consequences of losing both organizational and geographical proximity. European Planning Studies. 15 (2), 271-288.

5. Drury, K. Introduction to managerial and cost accounting / / Audit, Unity. - 1998.

6. Elshankskaya D. (2012): The improvement of accounting processes with regard to the development of outsourcing relations in RZD JSC (Russian Railways). Research Journal of Higher Attestation Commission of Russia "Bulletin SSTU" \# 1 (\#15). - Samara, 55-61. (Елшанская А.A. Совершенствование учётных процессов фоормирования аутсорсинговых отношений в ОАО «РЖА». Вестник Самарского государственного университета путей сообщения. - № 1 (15), 2012 - 55-61 стр).

7. Gilley, K., Rasheed, A., (2000). Making more by doing less: an analysis of outsourcing and its effects on firm performance. Journal of Management. 26 (4), 763-790.

8. Grossman, G., (2005). Outsourcing in a Global Economy. Review of Economic Studies. 72, 135-159.

9. Guilding, C., (1999). Competitor-focused accounting: an exploratory note. Accounting, Organizations and Society. 24, 583-595.

10. Heywood, J., (2001). The Outsourcing Dilemma: The Search for Competitiveness. Financial Times/ Prentice Hall.

11. Jiang, B., Belohlav, J., Young, T, (2007). Outsourcing impact on manufacturing firms's value: evidence from Japan. Journal of Operation Management. 25, 885-900.

12. Jiang, B., Frazier, G., Prater, L., (2006). Outsourcing effects on firms' operational performance an empirical study. International Journal of Operation \& Production Management. 26 (12), 1280-1300.

13. Kotliarov, I. (2010) Decision-making about the use of outsourcing based on an assessment of its effect for the enterprise. Innovations. 9, 88-92.

14. Lamminmaki, D., (2008). Accounting and the management of outsourcing: An empirical study in the hotel industry. Management Accounting Research.19, 163-181. 
15. Lamminmaki, D. (2011). An examination of factors motivating hotel outsourcing. International Journal of Hospitality Management. 30, 963-973.

16. Larson, P., D., Kulchitsky, J., D., (1999). Logistics improvement programs the dynamics between people and performance. International Journal of Physical Distribution \& Logistics Management. 29 (2), 88-102.

17. Marx, K. (1867). Capital, Volume I: The Process of Production of Capital. Progress Publishers, Moscow, USSR

18. Power, D., Sharafali, M., Bhakoo, V., (2006). Adding value through outsourcing contribution of 3PL services to customer performance. Management Research News. 30 (3), 228-235

19. Salimath, M., Cullen, J., Umesh, U., (2008). Outsourcing and performance in entrepreneurial firms: contingent relationships with entrepreneurial configurations. Decision Sciences. 39 (3), 359-381.

20. Sheremet A. Managerial accounting: case study. - Moscow: FBK-Press, 2000

21. Sorokina, N. Mechanism of the realization of outsourcing on performance enterprises: Syllabus of the Doctoral dissertation. - Orenburg: Orenburg State Universitry, 2008

22. Wernerfelt, B., (1984). A resource-based view of the firm. Strategic Management Journal. 5 (2), $62-73$.

23. Williamson, E., (1981). The Economics of Organization: The Transaction Cost Approach. The American Journal of Sociology. 87(3), 548-577

\section{AUTHOR}

D. Meyr is from the Technische Universität Dresden, Faculty of Business and Economics from the Chair of Environmental Management and Accounting (e-mail: daria.meyr@mailbox.tu-dresden.de) 